\title{
Vaccination against pathogenic clostridia in animals: a review
}

\author{
Lida Abdolmohammadi Khiav ${ }^{1}$ (I) $\cdot$ Azadeh Zahmatkesh $^{1}$ (I)
}

Received: 8 July 2020 / Accepted: 12 April 2021 / Published online: 23 April 2021

(C) The Author(s), under exclusive licence to Springer Nature B.V. 2021

\begin{abstract}
Clostridium is a Gram-positive, rod-shaped, anaerobic, and spore-forming bacterium, which is found in the surrounding environments throughout the world. Clostridium species cause botulism, tetanus, enterotoxaemia, gas gangrene, necrotic enteritis, pseudomembranous colitis, blackleg, and black disease. Clostridium infection causes severe economic losses in livestock and poultry industries. Vaccination seems to be an effective way to control Clostridial diseases. This review discusses the toxins and vaccine development of the most common pathogenic Clostridium species in animals, including Clostridium perfringens, Clostridium novyi, Clostridium chauvoei, and Clostridium septicum. In this comprehensive study, we will review different kinds of clostridial toxins and the vaccines that are experimentally or practically available and will give a short description on each vaccine focusing on its applications, advantages, and disadvantages.
\end{abstract}

Keywords Clostridium $\cdot$ Toxin $\cdot$ Vaccine $\cdot$ Immunogenic $\cdot$ Veterinary

\section{Introduction}

Clostridium is a Gram-positive, rod-shaped, anaerobic, and spore-forming bacterium. Clostridium consists of around 250 species, which can be found in different environments in the world. Some cases of Clostridium infections have been reported since years ago. Clostridium infection causes severe economic losses in livestock and poultry industries and wild life. Some Clostridium species are the cause of disease in humans due to the release of exotoxins (e.g. tetanus, botulism, food poisoning, gas gangrene). Also, some Clostridium species are important in animals as causative agents of enterotoxaemia, gas gangrene, necrotic enteritis, blackleg, and black disease. Clostridium exotoxins cause mild to severe damage in gastrointestinal tract, soft-tissues, and nervous system (Carter et al. 2014). Practices with improper hygiene control and the lack of vaccination are important causes of clos-

Lida Abdolmohammadi Khiav

L.mohammadi@rvsri.ac.ir

1 Department of Anaerobic Vaccine Research and Production, Razi Vaccine and Serum Research Institute, Agricultural Research, Education and Extension Organization, Shahid Beheshti Blvd., P.O. Box: 31975/148, Hesarak, Karaj, Alborz Province, Iran tridial disease in human and animals. Hence, regular vaccination is an effective way to control clostridial infection in the world.

In this review, the clostridial important toxins are listed and their 3D structures (accessed by PHYRE2 and SWISSMODEL servers) as well as their genetic origins are presented (Fig. 1). Also, the main clostridial species used in vaccine research and industry are described and different types of available commercial and experimental vaccines are explained.

\section{Clostridium perfringens}

Clostridium perfringens is a straight or slightly curved rodshaped and non-motile bacterium, with blunt ends, which is arranged singly or in pairs, with $0.6-2.4 \mu \mathrm{m}$ width and 1.3 $19.0 \mu \mathrm{m}$ length. On sheep blood agar, large flat and roughedged or smooth and domed colonies can be observed with large zones of partial haemolysis out of narrow zones of complete haemolysis. They are very pleomorphic and sensitive to oxygen pressure (Brazier et al. 2002). The C. perfringens species is classified into six isotypes including A, B, C, D, E, and $\mathrm{F}$ based on their major toxins, iota ( $i a)$, alpha ( $c p a)$, beta ( $c p b)$, and epsilon (etx) (Kiu and Hall 2018). Only types A, C, and F have been determined to cause disease in humans, whereas all of the types have been demonstrated to cause disease in 
animals ( $\mathrm{Li}$ et al. 2016). C. perfringens also produces other toxins such as enterotoxin (cytotoxin), necrotic enteritis betalike toxin, delta (hemolysin), teta or perfringolysin (hemolysin $\left(\mathrm{O}_{2}\right.$ labile), cytolysin), kappa (collagenase, gelatinase), lambda (protease), mu (hyaluronidase), nu (deoxyribonuclease), gamma, eta, and neuraminidase (sialidase) (McDonel 1980). Structures of clostridial major and minor toxins are presented in Fig. 1. A brief description of some of its toxins is defined below:

\section{Alpha toxin or phospholipase C}

Chromosome-encoded alpha toxin $(43 \mathrm{kDa})$ is produced by all types of $C$. perfringens. Alpha toxin has local effects on the cell membrane and, finally, leads to endocytosis and cell death (Oda et al. 2015). C. perfringens type A causes traumatic clostridial myonecrosis in both humans and animals (Stevens et al. 2012), food poisoning and gas gangrene in humans, enterotoxaemia in lambs (yellow lamb disease), and
Fig. 1 3D structure of clostridial major toxins and their genetic origins

\section{C. perfringens ITXa}

C. perfringens CPA

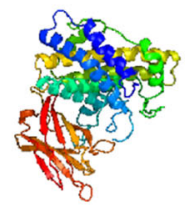

C. perfringens CPE

C. perfringens ITXb

Bacterial chromosome

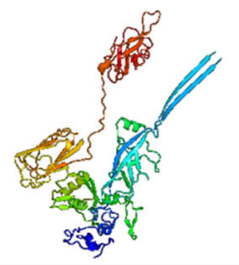

C. perfringens ETX

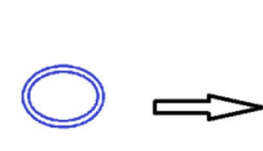

Plasmid

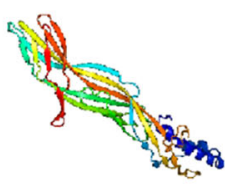

C. perfringens NetB

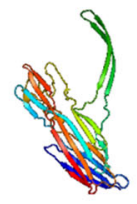

C. perfringens CPE

C. perfringens CPB
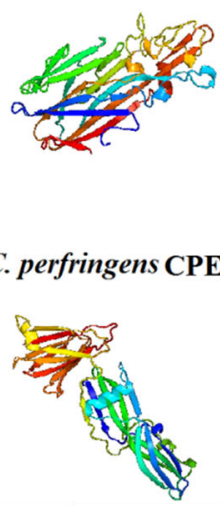

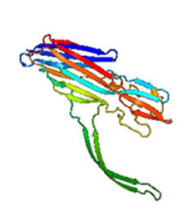

C. perfringens $\mathrm{TpeL}$

C. perfringens CPB2
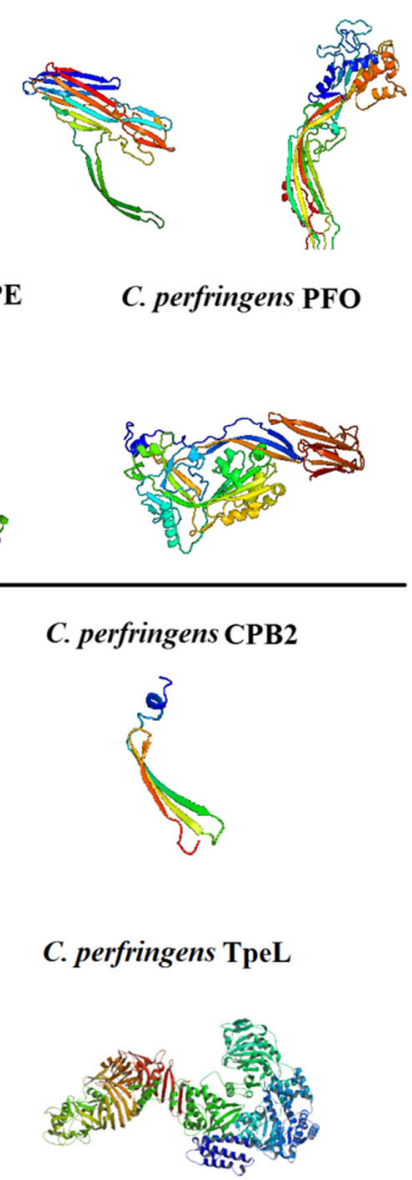

C. perfringens $\mathrm{PFO}$
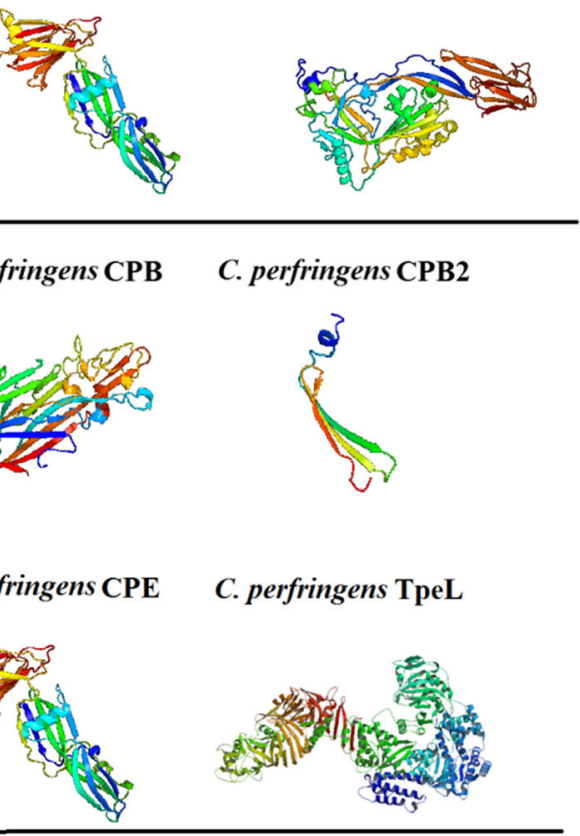

\section{Phage}

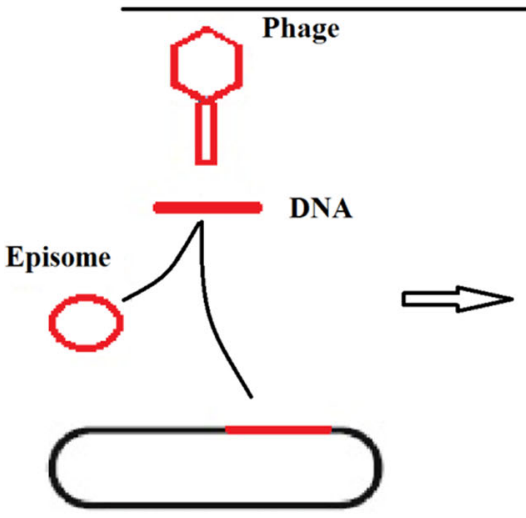

C. novyi TenA

Bacterial chromosome

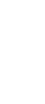


enteritis or enterotoxaemia in cattle, pigs, horses, and goats. However, the role of alpha toxin for intestinal disease is controversial (Goossens et al. 2014). This toxin is responsible for necrotic enteritis in chickens (Sawires and Songer 2006), but its role is also controversial (Keyburn et al. 2008).

\section{Epsilon toxin}

Plasmid-borne epsilon toxin (ETX) is produced by $C$. perfringens type $\mathrm{D}$ and $\mathrm{B}$ strains, which cause fatal enterotoxaemia (pulpy kidney) in sheep and goats (Uzal et al. 2014). This toxin is associated with sudden change and large consumption of carbohydrates, which allow the rapid growth of $C$. perfringens strains (Songer 1996). The accumulation of the active toxin $(29 \mathrm{kDa})$ in the intestine increases permeability of the animal intestinal epithelium, and then, the toxin is absorbed into the bloodstream and spreads to other organs, such as the brain, lungs, and kidneys (Popoff 2011).

\section{Beta toxin}

Plasmid-borne $C$. perfringens beta toxin (CPB) is produced by $C$. perfringens type $\mathrm{B}$ and $\mathrm{C}$ strains. C. perfringens type $\mathrm{B}$ causes lamb dysentery, and $C$. perfringens type $\mathrm{C}$ causes enterotoxaemia and necrotic enteritis in domestic animal newborns. Beta toxin forms an oligomeric complex that channels into the cell membrane, enters into the bloodstream (Nagahama et al. 2015), and causes necrosis of the small intestine, toxaemia, and shock (Uzal et al. 2014).

\section{Beta2 toxin}

The CPB2 is produced by all types of $C$. perfringens. The cpaencoding gene has been characterized in strains of C. perfringens types A-E. C. perfringens type $\mathrm{D} c p b 2$ gene is encoded by $48-110-\mathrm{kb}$ plasmids. In $C$. perfringens type $\mathrm{E}$ isolates, $c p b 2$ gene is located on 70-90-kb plasmids. Also, $C$. perfringens type $\mathrm{B} c p b 2$ gene is located on a $65-\mathrm{kb}$ plasmid that also carries the etx gene (Uzal et al. 2010). Beta2 is a poreforming toxin, which causes enteritis in neonatal pigs and diarrhoea in horses (El-sify 2015).

\section{ITX}

Iota toxin is a binary toxin including Ia (an enzymatic component) (45 kDa) and $\mathrm{Ib}$ (a binding component) (100 kDa). The ITX components are encoded by iap ( 1160 nt) and iab ( $\sim 2630 \mathrm{nt})$ genes. Ib section binds to a surface receptor on the target cells and then heptamerizes to form channels, allowing the enzymatic component (Ia) to translocate into the cytosol disrupting the cell cytoskeleton (Takehara et al. 2017). Iota toxin causes increased vascular permeability, which is associated with hemorrhagic enteritis (Uzal et al. 2010).

\section{CPE}

The gene (cpe) encoding C. perfringens enterotoxin (CPE) is encoded either on the chromosome or on the plasmid. CPE is a pore-forming toxin $(\sim 34 \mathrm{kD})$ and has one free sulfhydryl group (Granum et al. 1981), which is produced by $C$. perfringens types $\mathrm{A}$ and $\mathrm{E}$ and some isolates of types $\mathrm{C}$ and D. C. perfringens type A isolates are divided to two cpe plasmid families: a $\sim 75-\mathrm{kb}$ plasmid family that carries the beta 2 toxin gene and a $\sim 70-\mathrm{kb}$ plasmid family lacking the beta 2 toxin gene (Uzal et al. 2010). The toxin binds to claudin receptors on the target cells, forming pores in the cell membrane, allowing an unregulated influx of calcium, which leads to necrosis (Freedman et al. 2016). CPE is responsible for food poisoning, sporadic diarrhoea, antibiotic-associated diarrhoea, and sudden infant death syndrome in humans (Lindström et al. 2011); however, the role of cpe gene for gastrointestinal disease in animals is not clear (Uzal et al. 2010).

\section{NetB}

Plasmid-borne necrotic enteritis beta-like toxin (NetB) is produced by $C$. perfringens type A isolates (Keyburn et al. 2010). $\mathrm{NetB}$ is a $\beta$-pore-forming toxin $(33 \mathrm{kDa})$ with 323 amino acids, which is an important virulence factor involved in necrotic enteritis in birds (Keyburn et al. 2008). Seven NetB monomers make a heptameric structure that forms channels in phospholipid bilayers (Rood et al. 2016) allowing cations to enter the cell, resulting in cell rounding and lysis (Yan et al. 2013).

\section{C. perfringens large cytotoxin (TpeL)}

TpeL is produced by $C$. perfringens type $\mathrm{A}, \mathrm{B}$, and $\mathrm{C}$ strains (Amimoto et al. 2007). C. perfringens type $\mathrm{B}$ and type $\mathrm{C}$ TpeL toxins are encoded by plasmids ranging from $60-65 \mathrm{~kb}$ to $~$ $90 \mathrm{~kb}$. There is no information about TpeL toxin of C. perfringens type A isolates (Sayeed et al. 2010). TpeL toxin is the largest $C$. perfringens toxin. TpeL toxin binds to LDL receptor-related protein 1 in host cells and enters the target cell by endocytosis. Then, the toxin enters to endosomal membrane and releasing the DXD fragment (glycosylating domain, which is located in the $\mathrm{N}$-terminal region) into the cytosol. DXD fragment modifies the regulatory GTPase (including Rac1, Ras, Rap and Ral) and disrupts the regulation of the actin cytoskeleton leading to disaggregation of the intercellular connections and then cell death (Nagahama et al. 2012). The role of TpeL is not obviously known, but it has been mentioned that TpeL might have been associated with avian necrotic enteritis (Coursodon et al. 2012). 


\section{Teta toxin or PFO}

The gene (pfoA) encoding perfringolysin $\mathrm{O}(\mathrm{PFO})$ is located on the chromosomal DNA near the origin of replication (Shimizu et al. 2002). PFO is produced by all types of C. perfringens. The molecular weight of the PFO is $54 \mathrm{kDa}$ and consists of four domains and a 27 -amino acid signal peptide (Tweten 1988). The C-terminal domain binds to cholesterol and causes conformational changes in other domains and insertion in membrane (Shepard et al. 2000). PFO has been associated with gas gangrene and bovine necrohemorrhagic enteritis (Awad et al. 2001; Verherstraeten et al. 2013).

\section{Clostridium novyi}

C. novyi or C. oedematiens is a Gram-positive rod-shape and motile bacterium with the dimensions of 1.1-2.5 $\times 3.3-22.5$ $\mu \mathrm{m}$. C. novyi is a fastidious bacterium due to its obligate anaerobic conditions (Moore 1968). On blood agar, colonies are small, flat, rough or rhizoidal, translucent and $\beta$ haemolytic for $48-72 \mathrm{~h}$ (Brazier et al. 2002). C. novyi is classified into four different types, including $\mathrm{A}, \mathrm{B}, \mathrm{C}$ and $\mathrm{D}$. C. novyi type B and A produce alpha toxin (TcnA) (Fig. 1), which has glycosyltransferase activity that modifies small GTP-binding proteins and causes is responsible for cell rounding (Selzer et al. 1996). The gene encoding TcnA is located on the prophage genome in C. novyi strains (Skarin and Segerman 2014). This bacteriophage is responsible to regulate toxin production (Fortier 2017). Also, C. novyi type $B$ produces beta toxin, that has phospholipase activity (Hauer et al. 2004). C. novyi type B causes black disease, which is an acute toxaemia especially in sheep and cattle (Navarro and Uzal 2016).

\section{Clostridium chauvoei}

Clostridium chauvoei is a straight rod-shape bacterium with rounded ends and $0.6 \times 3-8 \mu \mathrm{m}$ dimensions, which is arranged singularly or in short chains of bacteria and is motile by peritrichous flagella. On the sheep blood agar, it forms large ( $5 \mathrm{~mm}$ in diameter) colonies, with hemolysis. Clostridium chauvoei toxin A (CctA) is the major virulence factor (Frey et al. 2012) with molecular mass of $32.2 \mathrm{kDa}$, which causes cell lysis by increase in permeability of the animal tissue (Nicholson et al. 2019). Other virulence factors are associated with the pathogenesis including neuraminidase/ sialidase NanA, beta toxin-DNAse, oxygen-labile hemolysin $\mathrm{D}$ (or hemolysin III), hyaluronidase Nag (previously called $\gamma$ toxin), and flagella. C. chauvoei is responsible for blackleg in cattle and rarely in small ruminants, which spreads in a short time and kills the animals (Frey et al. 2012).

\section{Clostridium septicum}

Clostridium septicum is Gram-positive, rod-shape bacteria with numerous sub-terminal spores. On blood agar, they usually produce a thick haemolytic swarming growth (Brazier et al. 2002). C. septicum produces four toxins, namely, alpha, beta, gamma, and delta. Alpha toxin (ATX) (Fig. 1) is the major virulence factor, encoded by the csa gene (Kennedy et al. 2009). Alpha toxin has lethal, haemolytic, and necrotizing activities. Beta toxin (desoxyribonuclease) has enzymatic activity. Gamma toxin is also an enzyme. Delta toxin has necrotizing activity, which can be demonstrated by intracutaneous inoculation of guinea pigs. C. septicum is responsible for myonecrosis in humans and braxy and malignant oedema (gas gangrene) in ruminants and clostridial dermatitis in poultry (Zaragoza et al. 2019). C. septicum causes severe economic losses in livestock and poultry industries.

\section{Vaccine production}

Vaccination is one of the most effective methods to prevent diseases. A vaccine helps the body's immune system identify and eradicate the life-threatening pathogens such as Clostridium species. Clostridial vaccines have been proven to be effective in domestic animals including cattle, sheep, and goats (Springer and Selbitz 1999) and have been noted to be available since the 1950s (Sargison 2009). These vaccines are effective for the most common clostridial diseases, including pulpy kidney, black disease, and malignant oedema. However, vaccination against $C$. chauvoei has been reported as a common protective method since 1930 , especially in cattle herds. A summary of commercial and experimental vaccines available in the world and Iran is described in Table 1.

Generally, clostridial vaccines (except $C$. chauvoei) contain one or more exotoxins produced by $C$. perfringens, C. novyi, and C. septicum. Commercial C. chauvoei vaccines consist of whole formalin-inactivated bacterial cultures, which are presented as monovalent or in combination with other clostridial agents (Zaragoza et al. 2019).

Evaluation of economic losses caused by $C$. septicum is hard due to the lack of data. However, a severe damage can be estimated because of high mortality rate (Baldassi et al. 1985). The control of C. septicum is based on preventive measurements and vaccination of the herd (Thachil et al. 2013). For black disease, the economic losses can be inhibited by administration of $C$. novyi vaccines in animals; however, control of fascioliasis is very important in the controlling program of black disease.

Clostridial vaccines have been produced in different methods with different efficiencies and advantages or disadvantages. Different types of vaccines available for each 
Table 1 Comparison of commercial and experimental vaccines in the world and Iran.

\begin{tabular}{|c|c|c|c|c|c|}
\hline Strain & $\begin{array}{c}\text { Commercial } \\
\text { vaccine in the } \\
\text { world }\end{array}$ & $\begin{array}{c}\text { Commercial } \\
\text { vaccine in } \\
\text { Iran }\end{array}$ & $\begin{array}{c}\text { Experimental } \\
\text { vaccines in the } \\
\text { world }\end{array}$ & $\begin{array}{c}\text { Experimental } \\
\text { vaccines in } \\
\text { Iran }\end{array}$ & $\begin{array}{l}\text { Target } \\
\text { animals }\end{array}$ \\
\hline \multirow[b]{2}{*}{$\begin{array}{l}\text { C. perfringens } \\
\text { type A }\end{array}$} & \multirow[b]{2}{*}{$\begin{array}{c}\text { toxoid vaccine } \\
\text { (Zaragoza et al. } \\
\text { 2019) }\end{array}$} & \multirow[b]{2}{*}{ Not produced } & $\begin{array}{c}\text { recombinant } \\
\text { CPA(Nagahama } \\
\text { et al. 2013) }\end{array}$ & $\begin{array}{l}\text { recombinant } \\
\text { CPA, NetB } \\
\text { and tpeL } \\
\text { (Rostami et } \\
\text { al. 2016) }\end{array}$ & \multirow[b]{2}{*}{$\begin{array}{r}\text { Cattle and } \\
\text { polutry }\end{array}$} \\
\hline & & & $\begin{array}{c}\text { recombinant } \\
\text { CPA, CPB, } \\
\text { ETX, and NetB } \\
\text { (Zaragoza et al. } \\
\text { 2019) } \\
\text { Recombinant } \\
\text { NetB (Keyburn } \\
\text { et al. 2013) }\end{array}$ & $\begin{array}{l}\text { Recombinant } \\
\text { cpe C- } \\
\text { terminal } \\
\text { (Taherian } \\
\text { Fard et al. } \\
\text { 2010) }\end{array}$ & \\
\hline \multirow[t]{2}{*}{$\begin{array}{l}\text { C. perfringens } \\
\text { type B }\end{array}$} & $\begin{array}{l}\text { toxoid vaccine } \\
\text { (Moreira et al. } \\
2016 \text { ) or } \\
\text { bacterin-toxoid } \\
\text { vaccine }\end{array}$ & $\begin{array}{l}\text { bacterin-toxoid } \\
\text { vaccine } \\
\text { (Ardehali and } \\
\text { Darakhshan } \\
\text { 1976, Ardehali }\end{array}$ & $\begin{array}{c}\text { recombinant } \\
\text { ETX (Zaragoza } \\
\text { et al. 2019) }\end{array}$ & $\begin{array}{l}\text { recombinant } \\
\text { CPB (Bakhshi } \\
\text { et al. 2016) }\end{array}$ & $\begin{array}{r}\text { Domestic } \\
\text { animals }\end{array}$ \\
\hline & $\begin{array}{l}\text { (Zaragoza et al. } \\
\text { 2019) }\end{array}$ & $\begin{array}{c}\text { and } \\
\text { Darakhshan } \\
\text { 1977) }\end{array}$ & $\begin{array}{c}\text { CPB (Zaragoza } \\
\text { et al. 2019) } \\
\text { recombinant } \\
\text { CPA, CPB, } \\
\text { ETX (Jiang et } \\
\text { al. 2014) } \\
\text { recombinant } \\
\text { fused ETX- } \\
\text { CPB (Zaragoza } \\
\text { et al. 2019) }\end{array}$ & $\begin{array}{l}\text { recombinant } \\
\text { TpeL } \\
\text { (Mamandi et } \\
\text { al. 2019) }\end{array}$ & \\
\hline $\begin{array}{l}\text { C. perfringens } \\
\text { type C }\end{array}$ & $\begin{array}{c}\text { toxoid vaccine } \\
\text { (Springer and } \\
\text { Selbitz 1999) or } \\
\text { bacterin-toxoid } \\
\text { vaccine } \\
\text { (Zaragoza et al. } \\
\text { 2019) }\end{array}$ & $\begin{array}{l}\text { bacterin-toxoid } \\
\text { vaccine } \\
\text { (Ardehali and } \\
\text { Darakhshan } \\
\text { 1976, Ardehali } \\
\text { and } \\
\text { Darakhshan } \\
\text { 1977) }\end{array}$ & $\begin{array}{c}\text { recombinant } \\
\text { CPB (Milach et } \\
\text { al. 2012) } \\
\text { Recombinant } \\
\text { CPA, CPB } \\
\text { (Salvarani et al. } \\
\text { 2013) } \\
\text { Recombinant } \\
\text { fused CPA, } \\
\text { CPB, CPB2 } \\
\text { (Zeng et al. } \\
\text { 2011) }\end{array}$ & Not done & $\begin{array}{r}\text { Domestic } \\
\text { animals }\end{array}$ \\
\hline $\begin{array}{l}\text { C. perfringens } \\
\text { type D }\end{array}$ & $\begin{array}{c}\text { toxoid vaccine } \\
\text { (Kennedy et al. } \\
1977, \\
\text { Moreira et al. } \\
\text { 2016) or } \\
\text { bacterin-toxoid } \\
\text { vaccine } \\
\text { (Zaragoza et al. }\end{array}$ & $\begin{array}{l}\text { bacterin-toxoid } \\
\text { vaccine } \\
\text { (Ardehali and } \\
\text { Darakhshan } \\
\text { 1976, Ardehali } \\
\text { and } \\
\text { Darakhshan } \\
\text { 1977) }\end{array}$ & $\begin{array}{l}\text { recombinant } \\
\text { ETX (Lobato, } \\
\text { et al. 2010) }\end{array}$ & $\begin{array}{l}\text { recombinant } \\
\text { ETX } \\
\text { (Aziminia et } \\
\text { al. 2016) } \\
\text { recombinant } \\
\text { fused ETX- } \\
\text { CPB } \\
\text { (Langroudi et }\end{array}$ & $\begin{array}{r}\text { Domestic } \\
\text { animals }\end{array}$ \\
\hline
\end{tabular}




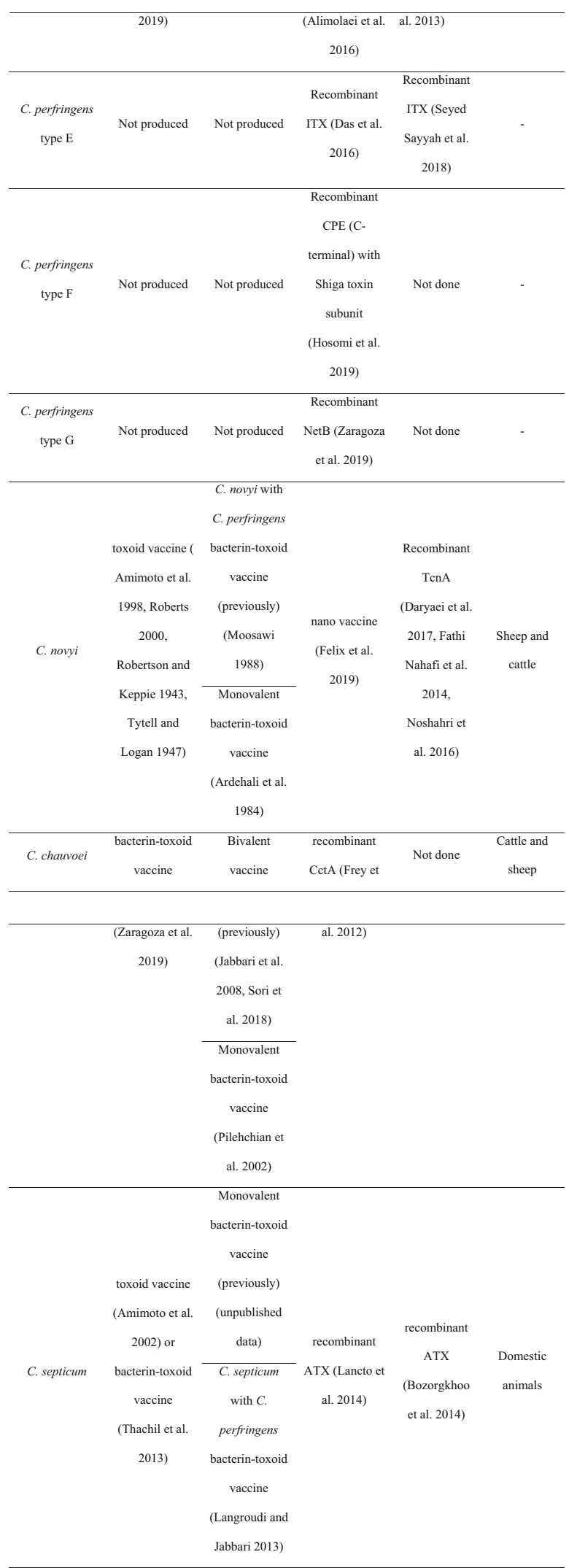


clostridial disease mentioned in this review are presented as follows:

\section{Whole formalin-inactivated vaccines}

The production of the vaccine is achieved by culture of C. chauvoei strains in a fermenter using complex media containing casein hydrolysate, peptone, tryptone, yeast extract, and meat extract, $\mathrm{NaOH}$, L-cysteine hydrochloride, glucose plus trace element, and vitamin for approximately $9 \mathrm{~h}$ at 37 ${ }^{\circ} \mathrm{C}$ and then inactivation by formaldehyde for approximately 6 days at $37^{\circ} \mathrm{C}$ (Langroudi et al. 2012; Pilehchian et al. 2002). The efficacy of the blackleg vaccine has been surveyed in challenged vaccinated and unvaccinated cattle (control group). This study has shown that no cases of disease were found in the vaccinated cattle, while some unvaccinated cattle died or became ill. A significant difference between vaccinated and unvaccinated animals has been observed (Haghroosta et al. 2014).

\section{Bacterin-toxoid vaccines}

Bacterin-toxoid vaccine is produced by culture of C. perfringens type $\mathrm{D}, \mathrm{B}$, and $\mathrm{C}$ strains separately in fermenter using complex media containing peptone, yeast extract, glucose, or dextrin, vitamins, and trace element in anaerobic conditions for approximately 4-5 h. Finally, the whole culture is chemically inactivated using formaldehyde treatment (Ardehali and Darakhshan 1976).

For black disease vaccine, bacterin-toxoid vaccine has been produced by culture of $C$. novyi strains in glass bottles using complex media containing peptone or other protein sources, L-cysteine, maltose, and $\mathrm{NaOH}$ for approximately $72 \mathrm{~h}$ at 37 ${ }^{\circ} \mathrm{C}$ and inactivation of TcnA by formaldehyde at $37^{\circ} \mathrm{C}$ for 3 days (Ardehali et al. 1984; Ardehali et al. 1986). Nowadays, production of the bacterin-toxoid vaccine is achieved by growing vaccine strain in fermenters containing peptone, Lcysteine, maltose, $\mathrm{NaOH}$, vitamins and trace element, Tween 80 , and glycerol in anaerobic conditions for approximately $24 \mathrm{~h}$ at $37^{\circ} \mathrm{C}$ and inactivation by formaldehyde at $37^{\circ} \mathrm{C}$ (Fathi Najafi et al. 1398).

For production of vaccine against $C$. septicum, the stains are cultured in anaerobic conditions in a fermenter using complex media such as meat peptones, tryptone, yeast extract, casein hydrolysate, glucose, trace elements and vitamins, Lcysteine hydrochloride, and $\mathrm{NaOH}$ at $37{ }^{\circ} \mathrm{C}$ with $\mathrm{pH}$ of 7.27.4 for approximately $9 \mathrm{~h}$ and inactivation by formaldehyde at $37{ }^{\circ} \mathrm{C}$ (Langroudi and Jabbari 2013).

Bacterin-toxoid vaccines have good efficiency due to the bacterial cell compartments leading to a high immune response against all the infection-associated antigens. Some of these vaccines are available without any additional inducing agents or adjuvants. However, some antibodies will be produced against some non-important parts of the pathogen with no specific function related to the disease and so impose extra burden to the immune system. This may decrease the efficiency of the adaptive immunity in specifically triggering the pathogenic factors. Killed vaccines usually require adjuvant and several injections (Baxter 2007).

\section{Toxoid vaccines}

Formaldehyde-inactivated $C$. perfringens supernatant (crude toxoid) has been produced by Lovland and his colleagues and they have proven that $C$. perfringens type $\mathrm{A}$ or $\mathrm{C}$ or combined type $\mathrm{A}$ and $\mathrm{C}$ crude toxoids are significantly successful in protection against infection (Lovland et al. 2004).

The ETX and CPB toxoid vaccine has been prepared from the inactivated cultures using ammonium sulfate to control enterotoxaemia in animals throughout the world (Fisher et al. 2006). Also, NetB toxoid vaccine has been able to protect against necrotic enteritis (da Costa et al. 2013). Additionally, alpha toxin (CPA) toxoid vaccine (NETVAX®, Schering-Plough) has been also prepared to protect against necrotic enteritis in birds (Fernandes da Costa et al. 2016). Different research have proved that the control of clostridial disease by administration of a $C$. perfringens toxoid vaccine has been effective in animals including piglets, cattle, lambs, sheep, and goats (Kennedy et al. 1977; Springer and Selbitz 1999).

Crude alpha-toxoid vaccines have been prepared using inactivated culture supernatant of Clostridium strains (Amimoto et al. 1998). C. novyi type B alpha-toxin was purified using column chromatography, inactivated by formaldehyde, mixed with aluminium phosphate (as gel adjuvant), and then administered to guinea pigs. Alpha antitoxin protective efficiency was estimated by challenge with $C$. novyi type B spores. Results showed that $C$. novyi vaccine (toxoid) was protective against challenge in guinea pigs (Amimoto et al. 1998).

In another effort, the inactivated culture was concentrated and purified by salting out or molecular filtration. Then, the residual agent was neutralized using sodium bisulfite solution. Finally, a multicomponent toxoid vaccine was prepared by mixing seven strains of Clostridium and saponin as gel adjuvant. The prepared vaccine was administered to cattle intramuscularly or subcutaneously. Also, the formulated vaccine was evaluated by potency tests in rabbits and guinea pigs. The result showed that the multicomponent toxoid vaccine was effective and safe without local reactions and had the potential to be used as a commercial vaccine (Roberts 2000). There are other studies that have proven the effectivity of toxoid vaccines in animals (Amimoto et al. 2002; Ardehali and Darakhshan 1976; Robertson and Keppie 1943).

C. septicum alpha toxin has been harvested, concentrated, purified, and inactivated by formalin, and the prepared alpha 
toxoid has been shown to protect guinea pigs against spores of C. septicum (Amimoto et al. 2002).

Since toxoid vaccines are free of any additional antigens such as proteins bound to the bacterial cell wall, and they are low molecular weight proteins, they are not highly immunogenic on their own unless they are inoculated in large amounts or multiple doses. Hence, they need addition of adjuvants to induce a sufficient adaptive immune response in the hosts. These pure toxoids are being demanded by the community, because of no extra burden on the host immune system and being safe due to not including any bacterial cells or spores and no chance of conversion to virulence. Also, toxoid vaccines are expected to be more stable than whole-culture bacterial vaccines, as they are less susceptible to changes in storage conditions such as light temperature and humidity (Baxter 2007).

\section{Genetically engineered vaccines}

NetB mutant vaccine as a non-formaldehyde genetically produced toxoid has been reported to decrease cytotoxicity and haemolytic activity, purposing the mutant vaccine as a candidate potent vaccine (da Costa et al. 2013). Furthermore, ETX non-toxic mutant vaccine (toxoid) has been synthesized and expressed in Lactobacillus casei cells. The bacterial suspension expressing the recombinant protein was used for immunization in mice. The results showed that this vaccine could be an effective candidate vaccine against enterotoxaemia (Alimolaei et al. 2016).

In recent years, research has been focused on experimental recombinant $C$. perfringens vaccines. The $E T X$ and $c p b$ gene regions of the $C$. perfringens have been used for design of the new generation vaccines, separately (Aziminia et al. 2016; Bakhshi et al. 2016). Recombinant vaccines expressed in E. coli have resulted in high immunity in laboratory animals (Aziminia et al. 2016; Lobato et al. 2010). Also, monovalent recombinant CPA has been prepared and evaluated. The result of study showed that the recombinant vaccine seems to be protective in mice (Nagahama et al. 2013). Experimental monovalent recombinant Iota and TpeL toxins have been expressed separately in E. coli (Mamandi et al. 2019; Seyed Sayyah et al. 2018). Monovalent recombinant vaccines against cpe $\mathrm{C}$-terminal region from $C$. perfringens type $\mathrm{A}$ strain did not show any systemic effect on BALB/c mice and guinea pigs (Taherian Fard et al. 2010). Moreover, it has been reported that recombinant NetB vaccine is effective against NetB infection in birds (Keyburn et al. 2013). Some recombinant multivalent vaccines have been prepared and compared to the traditional monovalent or bivalent vaccines (Goossens et al. 2016; Moreira et al. 2016; Salvarani et al. 2013). Pilehchian et al. proved that bivalent recombinant fused ETX-CPB vaccine seems to be protective in mice and rabbit (Langroudi et al. 2013). Furthermore, a study on bivalent recombinant CPE (C-terminal region) from $C$. perfringens and the subunit of the Shiga toxin (Escherichia coli) have shown that they were protective in mice (Hosomi et al. 2019). On the other hand, experimental trivalent recombinant CPA, NetB, and TpeL resulted in high antibody titre suggesting them as a candidate vaccine against clostridial disease (Rostami et al. 2016). Also, successful experimental tetravalent recombinant CPA, CPB, ETX, and NetB have been reported (Zaragoza et al. 2019). These research have shown that multivalent recombinant vaccines could be effective in comparison with traditional vaccines in immunization of animals (Goossens et al. 2016).

Bioinformatics and molecular biology studies have been conducted on the alpha toxin of $C$. novyi for identification of the most antigenic regions of the toxin. The result of this study has shown that recognition of a small fragment of alpha toxin with high affinity can produce higher immune responses than whole antigen (Fathi Nahafi et al. 2014). So, these experiments suggested that bioinformatics tools can increase the chances of production of highly antigenic vaccines (Fathi Nahafi et al. 2014).

Also, several experimental recombinant vaccines of C. novyi alpha toxin have been prepared and evaluated using immunological methods. Results have shown that antibody produced against recombinant proteins was more effective than that of normal toxin (Daryaei et al. 2017; Noshahri et al. 2016).

Soluble antigens are considered as immunogenic components associated with blackleg disease. CctA is the major virulence factor; hence, some experimental recombinant CctA vaccines have been developed and evaluated for the immune response against blackleg. Recombinant CctA vaccine has shown protective against challenge with virulent $C$. chauvoei strain. So, this toxin seems a valuable candidate for the design of a suitable vaccine (Frey et al. 2012). Also, a recombinant nanA containing the sialic acid-binding domain (CBM40) vaccine has been efficient against the $C$. chauvoei infection (Vilei et al. 2011). On the other hand, somatic antigens are considered as immunogenic components associated with the protection against $C$. chauvoei disease. Therefore, experimental recombinant vaccine has been developed and evaluated for protection against disease in mice. The results showed that poor immunity induced. So, a conformation-dependent epitope is important in immune response against blackleg (Kojima et al. 2000).

A recombinant alpha toxin (noncytolytic ATX) experimental vaccine has been made against $C$. septicum disease (Bozorgkhoo et al. 2014). The recombinant vaccine has been also compared to the traditional vaccine. ELISA analysis and challenge results showed higher antibody concentrations than native vaccine. The recombinant vaccine is inexpensive compared with traditional vaccines; so, it is a suitable candidate for new generation vaccine (Lancto et al. 2014). 
Genetically engineered vaccines seem to be promising candidates due to the decrease in the laborious works and multiple steps in the culture and production of bacterial vaccines. Production of recombinant vaccines against clostridial infections has been considered as a non-toxic, high-yielding process with superior stability and biosafety (Salvarani et al. 2013). However, the need for adjuvants for induction of host immune system remains for intramuscular inoculation of purified recombinant toxoids. Another disadvantage of purified recombinant proteins is that the production process for insoluble proteins is laborious and time-consuming with multiple steps of solubilization, refolding, and purification. Although immunization of animals with non-purified recombinant antigens (e.g. inclusion bodies or supernatant lysate) has been proposed as a good alternative (Moreira et al. 2016; Lobato et al. 2010), there is still a doubt for replacing these kinds of vaccines because of the presence of bacterial contents such as lipopolysaccharides (LPS) (Terpe 2006).

\section{Nanovaccines}

In recent years, much attention has been focused on nanovaccines using nanoparticles as inducing adjuvants for enhancing antigen presentation and stability in the host. Also, one of the important problems in production of vaccines consisting of pore-forming toxins is to convert toxins to nontoxic toxoids without significant changes in the protein structure and antigenic epitopes. Current methods used for detoxification such as chemical- and heat-mediated methods can change the toxin structure and reduce immunogenicity and vaccine potency (Parish and Cannon 1960; Metz et al. 2004; Cryz Jr et al. 1982). A red blood cell membrane-coated nanoparticle system has been used to inactivate pore-forming toxins without protein denaturation, by neutralizing the membrane-damaging activity of toxins. Mice vaccinated with this nanoparticle-detained toxin showed higher immune response than with heat-denatured toxin (Hu et al. 2013).

Water-oil nanoemulsion containing concentrated and formalin-inactivated $C$. novyi type B $\alpha$-toxin has been prepared and evaluated by alpha-toxin challenge in immunized mice. Necropsies of the liver, spleen, and other part of the body were also examined to determine the safety of the vaccine. Data suggested that the nanovaccine was efficient for promoting antigen delivery and protection against lethal doses of bacteria in immunized mice (Felix et al. 2019). The effect of chitosan nanoparticles has been studied on the efficiency of clostridial vaccines. The vaccine containing chitosan could stimulate humoral immunity 2-3 times higher than the nonchitosan toxoid vaccinated rabbits (Fathi Najafi et al. 2020) or non-immunized chickens (Ramadan et al. 2020). The results of nanovaccines should be compared with other vaccines currently used and their protective effects need to be evaluated in the field, to confirm their applicability. Possibly, it would be expected to use nanovaccines with no need to addition of adjuvants and yet obtain the desirable results after vaccination.

\section{Polyvalent vaccines}

Blackleg and hemorrhagic septicaemia vaccine have been produced in a traditional manner with anaphylactic shock or local inflammation for last years in Iran (unpublished data). Later, efforts were made to prepare a modified blackleg and hemorrhagic septicaemia vaccine, which showed no anaphylactic shock or local inflammation in laboratory animals or target animals. (Jabbari et al. 2008; Sori et al. 2018).

Different polyvalent clostridial vaccines are commercially or locally available including bacterin and/or toxoids of C. perfringens, C. novyi, C. septicum, C. chauvoei, C. sordellii, and also C. tetani. A study on two 9-valent clostridial vaccines has shown that the antibody titres were observed up to 90 days after second immunization and then decreased until becoming non-detectable at 6 months. Also toxoids of $C$. tetani and $C$. novyi type B were the most immuno-dominant antigens and C. septicum induced the lowest antibody response. Variable antibody response and shorter time period of antibody existence have led to the suggestion of antigenic competition in application of polyvalent vaccines (Rossi et al. 2018). That might be due to the suboptimal antigen presentation because of insufficient MHC-II binding of specific antigens, lower number of available $\mathrm{T}$ helper cells, and the presence of antigens in the vaccine that occupy the immune system (Dhungyel et al. 2014).

There has been no further information on the occurrence of this phenomenon while using polyvalent clostridial vaccines. Hence, it is worth focusing on the comparative studies on mono- and polyvalent clostridial vaccines to find the best number/volume/interval of doses for immunization or the optimum unit of each antigen in the polyvalent vaccine production.

\section{Conclusion}

Throughout the world, a wide variety of clostridial toxoid or bacterin-toxoid or whole culture vaccines are used to protect animals against diseases. Some of these vaccines have not been used at all in our country. For example, tetanus toxoid is not used as a monovalent vaccine in horses or as a polyvalent vaccine for immunization of goats and sheep in Iran. Also, C. haemolyticum has been used in parts of the world for protection against hepatitis infections of the liver, but it has not been used in Iran. In some other countries, a polyvalent vaccine consisting of $C$. perfringens types $\mathrm{B}, \mathrm{C}$, and $\mathrm{D}$, C. septicum, C. novyi, C. chauvoei, and C. sordellii has been used to immunize animals against the related diseases. In Iran, a monovalent blackleg vaccine, monovalent black disease, 
and polyvalent enterotoxaemia are available. The large-scale productions of clostridial vaccines have remained unchanged since the 1900s in the world. Nevertheless, it has been proven that the nanovaccines and recombinant vaccines are effective and can be potential alternatives to conventional vaccines in laboratory animals such as mice, rabbits or genie pigs; however, these vaccines are not commercially available yet, and their production has still several disadvantages compared with traditional vaccines. A major challenge in the development of an ideal vaccine lies in evoking immune system in the host. Perhaps, recent developments to improve clostridial vaccines include generation of mutants by recognition of clostridial target genes, as well as generation of DNA vaccines. Also, new vaccine formulations with appropriate adjuvants especially for toxoid vaccines are useful for augmentation of animal immune system. For new generation vaccines, it is important to consider purification and inactivation steps, antigen presentation and concentration, vaccine delivery and stimulation of specific immune responses especially to the polyvalent vaccines.

Author contribution LAK had the idea for the article, performed the literature search and prepared the original draft. AZ participated in literature search and critically revised the work.

Data availability Not applicable

\section{Declarations}

Ethics approval The manuscript does not contain clinical studies or patient data.

Consent to participate All the authors approved the final manuscript.

Consent for publication All the authors consented the final manuscript.

Conflict of interest The authors declare no competing interests.

\section{References}

Alimolaei, M., Golchin, M., and Daneshvar, H., 2016. Oral immunization of mice against Clostridium perfringens epsilon toxin with a Lactobacillus casei vector vaccine expressing epsilon toxoid, Infection, Genetics and Evolution, 40, 282-287

Amimoto, K. et al., 1998. The protective effect of Clostridium novyi type $\mathrm{B}$ alpha-toxoid against challenge with spores in guinea pigs, Journal of Veterinary Medical Science, 60, 681-685

Amimoto, K. et al., 2002. Protective effect of Clostridium septicum alpha-toxoid vaccine against challenge with spores in guinea pigs, Journal of Veterinary Medical Science, 64, 67-69

Amimoto, K. et al., 2007. A novel toxin homologous to large clostridial cytotoxins found in culture supernatant of Clostridium perfringens type C, Microbiology, 153, 1198-1206
Ardehali, M., and Darakhshan, H., 1976. Production and standardization of polyvalent Clostridium perfringens vaccine in Iran, Developments in biological standardization, 32, 31-34

Ardehali, M., and Darakhshan, H., 1977. Production and standarization of polyvalent Clostridium perfringens vaccine in Iran, Archives of Razi Institute, 29, 41-45

Ardehali, M., Darakhshan, H., and Moosawi, M., 1984. Production and standardization of Clostridium oedematiens vaccine in Iran, Archives of Razi Institute, 34,35, 23-26

Ardehali, M., Darakhshan, H., and Moosawi, M., 1986. Mass production and standardization of Clostridium oedematiens vaccine against black disease (infectious necrotic hepatitis) of sheep, Developments in biological standardization, 64, 137-140

Awad, M.M. et al., 2001. Synergistic effects of alpha-toxin and perfringolysin $\mathrm{O}$ in Clostridium perfringens-mediated gas gangrene, Infection and Immunity, 69, 7904-7910

Aziminia, P., Pilehchian-Langroudi, R., and Esmaeilnia, K., 2016. Cloning and expression of Clostridium perfringens type $\mathrm{D}$ vaccine strain epsilon toxin gene in E. coli as a recombinant vaccine candidate, Iranian Journal of Microbiology, 8, 226-231

Bakhshi, F., Langroudi, R.P., and Eimani, B.G., 2016. Enhanced expression of recombinant beta toxin of Clostridium perfringens type B using a commercially available Escherichia coli strain, Onderstepoort Journal of Veterinary Research, 83, 1-4

Baldassi, L. et al., 1985. Observações sobre a incidência de gangrena gasosa e carbúnculo sintomático durante 10 anos, 1970-79, no estado de São Paulo, Biológico, São Paulo, 51, 161-165

Baxter, D., 2007. Active and passive immunity, vaccine types, excipients and licensing, Occupational Medicine, 57, 552-556.

Bozorgkhoo, Z. et al., 2014. Molecular cloning of Clostridium septicum vaccine strain alpha toxin gene in $E$. coli, Archives of Razi Institute, $69,15-20$

Brazier, J. et al., 2002. Isolation and identification of Clostridium spp. from infections associated with the injection of drugs: experiences of a microbiological investigation team, Journal of Medical Microbiology, 51, 985-989

Carter, G.P. et al., 2014. Regulation of toxin production in the pathogenic clostridia, Molecular Microbiology, 91, 221-231

Coursodon, C. et al., 2012. TpeL-producing strains of Clostridium perfringens type A are highly virulent for broiler chicks, Anaerobe, 18, 117-121

Cryz Jr, S. J., Furer, E., and Germanier, R., 1982. Effect of chemical and heat inactivation on the antigenicity and immunogenicity of Vibrio cholerae, Infection and Immunology, 38, 21-26

da Costa, S.P.F. et al., 2013. Protection against avian necrotic enteritis after immunisation with NetB genetic or formaldehyde toxoids, Vaccine, 31, 4003-4008

Daryaei, F.A., Langroudi, R.P., and Golestani Eimani, B., 2017. Production and Evaluation of a New Recombinant Cloning Vector for the Clostridium novyi Type B Vaccine Strain Alpha Toxin Gene, EC Microbiology, 7, 106-111

Das, S. et al., 2016. Generation and characterization of recombinant bivalent fusion protein r-Cpib for immunotherapy against Clostridium perfringens beta and iota toxemia, Molecular Immunology, 70, 140148

Dhungyel, O., Hunter, J., and Whittington, R., 2014. Footrot vaccines and vaccination, Vaccine, 32, 3139-3146

El-sify, A., 2015. A review on Clostridium perfringens toxins with special reference to Beta 2 toxin, Journal of Current Veterinary Research, 9, 85-100

Fathi Nahafi, M. et al., 2014. Bioinformatics identification, cloning and partial purification of antigenic regions of Clostridium novyi alpha toxin for immunization. 12th International congress of Immunology \& Allergy of Iran, 2014 
Fathi Najafi, M. et al., 1398. Induction of alpha toxin production and reduction of time of cultivation of Clostridium novyi for vaccine production, Proceedings of the twentieth congress of Microbiology, Kerman, 1398

Fathi Najafi, M., Rahman Mashhadi, M., and Hemmaty, M., 2020. Effectiveness of Chitosan Nanoparticles in Development of Pentavalent Clostridial Toxoid Vaccine in Terms of Clinical Pathology Elements and Immunological Responses, Archives of Razi Institute, 75, 3, 385-395

Felix, M.K.C. et al., 2019. Inactivated alpha toxin from Clostridium novyi type B in nano-emulsion protect partially protects Swiss mice from lethal alpha toxin challenge, Scientific Reports, 9, 1-9

Fernandes da Costa, S.P. et al., 2016. Variable protection against experimental broiler necrotic enteritis after immunization with the Cterminal fragment of Clostridium perfringens alpha-toxin and a non-toxic NetB variant, Avian Pathology, 45, 381-388

Fisher, D.J. et al., 2006. Dissecting the contributions of Clostridium perfringens type $\mathrm{C}$ toxins to lethality in the mouse intravenous injection model, Infection and Immunity, 74, 5200-5210

Fortier, L.-C., 2017. The contribution of bacteriophages to the biology and virulence of pathogenic clostridia. In: Advances in Applied Microbiology, (Elsevier, 169-200)

Freedman, J.C., Shrestha, A., and McClane, B.A., 2016. Clostridium perfringens enterotoxin: action, genetics, and translational applications, Toxins, 8,73

Frey, J. et al., 2012. Cytotoxin CctA, a major virulence factor of Clostridium chauvoei conferring protective immunity against myonecrosis, Vaccine, 30, 5500-5505

Goossens, E. et al., 2014. Clostridium perfringens strains from bovine enterotoxemia cases are not superior in in vitro production of alpha toxin, perfringolysin $\mathrm{O}$ and proteolytic enzymes, BMC Veterinary Research, 10, 32

Goossens, E. et al., 2016. The C-terminal domain of Clostridium perfringens alpha toxin as a vaccine candidate against bovine necrohemorrhagic enteritis, Veterinary Research, 47, 52

Granum, P.E., Whitaker, J.R., and Skjelkvåle, R., 1981. Trypsin activation of enterotoxin from Clostridium perfringens type A fragmentation and some physicochemical properties, Biochimica et Biophysica Acta (BBA)-Protein Structure, 668, 325-332

Haghroosta, A. et al., 2014. Study on efficiency of blackleg vaccine in cattle in Khuzestan. province, Iran, Research Journal of Pharmaceutical, Biological and Chemical Sciences, 5, 1741-1746

Hauer, P.J., Yeary, T.J., and Rosenbusch, R.F., 2004. Cloning and molecular characterization of the beta toxin (phospholipase C) gene of Clostridium haemolyticum, Anaerobe, 10, 243-254

Hosomi, K. et al., 2019. Development of a bivalent food poisoning vaccine: augmented antigenicity of the C-terminus of Clostridium perfringens enterotoxin by fusion with the B subunit of Escherichia coli Shiga toxin 2, International Immunology, 31, 91-100

Hu, C-M.J. et al., 2013. Nanoparticle-detained toxins for safe andeffective vaccination. Nature Nanotechnology, 8, 933-938

Jabbari, A.R. et al., 2008. Preparation and evaluation of Improved blackleg and hemorrhagic septicemia vaccine,

Jiang, Z. et al., 2014. Induction of potential protective immunity against enterotoxemia in calves by single or multiple recombinant Clostridium perfringens toxoids, Microbiology and Immunology, $58,621-627$

Kennedy, K. et al., 1977. Vaccination of cattle and sheep with a combined Clostridium perfringens types C and D toxoid, American Journal of Veterinary Research, 38, 1515-1517

Kennedy, C.L. et al., 2009. Pore-forming activity of alpha-toxin is essential for Clostridium septicum-mediated myonecrosis, Infection and Immunity, 77, 943-951

Keyburn, A.L. et al., 2008. NetB, a new toxin that is associated with avian necrotic enteritis caused by Clostridium perfringens, PLoS Pathogens, 4, e26
Keyburn, A.L. et al., 2010. Association between avian necrotic enteritis and Clostridium perfringens strains expressing NetB toxin, Veterinary Research, 41, 1-8

Keyburn, A.L. et al., 2013. Vaccination with recombinant NetB toxin partially protects broiler chickens from necrotic enteritis, Veterinary Research, 44, 54

Kiu, R., and Hall, L.J., 2018. An update on the human and animal enteric pathogen Clostridium perfringens, Emerging Microbes \& Infections, 7, 1-15

Kojima, A. et al., 2000. Cloning and expression of a gene encoding the flagellin of Clostridium chauvoei, Veterinary Microbiology, 76, 359-372

Lancto, C.A. et al., 2014. A noncytolytic $\alpha$ toxin recombinant protein protects turkeys against Clostridium septicum challenge, Avian Diseases, 58, 566-571

Langroudi, R., and Jabbari, A., 2013. Production of Braxy vaccine by fermenter and enriched culture media, Journal of Veterinary Research, 68, 297-304

Langroudi, R., Jabbari, A., and Shoshtari, M., 2012. Large scale production of blackleg vaccine by fermenter and enriched culture medium in Iran, Archives of Razi Institute, 67, 43-49

Langroudi, R.P., Shamsara, M., and Aghaiypour, K., 2013. Expression of Clostridium perfringens epsilon-beta fusion toxin gene in $E$. coli and its immunologic studies in mouse, Vaccine, 31, 3295-3299

Li, J., Uzal, F.A., and McClane, B.A., 2016. Clostridium perfringens sialidases: potential contributors to intestinal pathogenesis and therapeutic targets, Toxins, 8,341

Lindström, M. et al., 2011. Novel insights into the epidemiology of Clostridium perfringens type A food poisoning, Food Microbiology, 28, 192-198

Lobato, F.C. et al., 2010. Potency against enterotoxemia of a recombinant Clostridium perfringens type D epsilon toxoid in ruminants, Vaccine, 28, 6125-6127

Lovland, A. et al., 2004. Maternal vaccination against subclinical necrotic enteritis in broilers, Avian Pathology, 33, 81-90

Mamandi, H., Golestani Eimani, B., and Pilehchian Langroudi, R., 2019. Cloning of Tpel Gene of Clostridium perfringens in E. coli, Modares Journal of Biotechnology, 10, 103-107

McDonel, J.L., 1980. Clostridium perfringens toxins (type a, b, c, d, e), Pharmacology \& Therapeutics, 10, 617-655

Metz, B. et al., 2004. Identification of formaldehyde-induced modifications in proteins: reactions with model peptides, Journal of Biological Chemistry, 279, 6235-6243

Milach, A. et al., 2012. Production and characterization of Clostridium perfringens recombinant $\beta$ toxoid, Anaerobe, 18, 363-365

Moore, W., 1968. Solidified media suitable for the cultivation of Clostridium novyi type B, Microbiology, 53, 415-423

Moosawi, M., 1988. Production and standardization two types of clostridial - vaccines for sheep and cattle, Archives of Razi Institute, 38, $39,83-88$

Moreira, G.M.S.G. et al., 2016. Immunogenicity of a trivalent recombinant vaccine against Clostridium perfringens alpha, beta, and epsilon toxins in farm ruminants, Scientific Reports, 6, 22816

Nagahama, M., Oda, M., and Kobayashi, K., 2012. Glycosylating Toxin of Clostridium perfringens. Glycosylation, 2012, IntechOpen,

Nagahama, M. et al., 2013. A recombinant carboxy-terminal domain of alpha-toxin protects mice against Clostridium perfringens, Microbiology and Immunology, 57, 340-345

Nagahama, M. et al., 2015. Recent insights into Clostridium perfringens beta-toxin, Toxins, 7, 396-406

Navarro, M., and Uzal, F.A., 2016. Infectious necrotic hepatitis, Clostridial Diseases of Animals. 1st ed. Ames, IA: Wiley Blackwell, 275-279

Nicholson, P. et al., 2019. Production of neutralizing antibodies against the secreted Clostridium chauvoei toxin A (CctA) upon blackleg vaccination, Anaerobe, 56, 78-87 
Noshahri, N.G. et al., 2016. Identification and cloning of highly epitopic regions of Clostridium novyi alpha toxin, Turkish Journal of Biology, 40, 1219-1226

Oda, M. et al., 2015. Membrane-binding mechanism of Clostridium perfringens alpha-toxin, Toxins, 7, 5268-5275

Parish, H. J. and Cannon, D. A., 1960. Staphylococcal infection: antitoxic immunity, British Medical Journal, 1, 743-747

Pilehchian, R., Moosawi, M., and Ardehali, M., 2002. Large scale cultivation of $C$. Chauvoei (blackleg) vaccine by fermenter. Proceedings of the the 3rd international Iran and Russia conference, Moscow, $2002,18-20$

Popoff, M.R., 2011. Epsilon toxin: a fascinating pore-forming toxin, The FEBS Journal, 278, 4602-4615

Ramadan, N.M. et al., 2020. Oral immunization of broilers with chitosan nano-encapsulated extracellular and cell wall proteins of necrotic enteritis-induced Clostridium perfringens, bioRxiv, 1-36

Roberts, D.S., 2000. Multicomponent clostridial vaccines using saponin adjuvants. 2000, Google Patents,

Robertson, M., and Keppie, J., 1943. Gas Gangrene. Active Immunisation by means of concentrated toxoids, Lancet, 311-314

Rood, J.I., Keyburn, A.L., and Moore, R.J., 2016. NetB and necrotic enteritis: the hole movable story, Avian Pathology, 45, 295-301

Rossi, A. et al., 2018. Temporal evolution of anti-Clostridium antibody responses in sheep after vaccination with polyvalent Clostridial vaccines. Veterinary Immunology and Immunopathology, 46-51

Rostami, A. et al., 2016. Design and expression of a chimeric vaccine candidate for avian necrotic enteritis, Protein Engineering, Design and Selection, 30, 39-45

Salvarani, F.M. et al., 2013. Vaccination with recombinant Clostridium perfringens toxoids $\alpha$ and $\beta$ promotes elevated antepartum and passive humoral immunity in swine, Vaccine, 31, 4152-4155

Sargison, N., 2009. Sheep flock health: a planned approach, (John Wiley \& Sons)

Sawires, Y.S., and Songer, J.G., 2006. Clostridium perfringens: insight into virulence evolution and population structure, Anaerobe, 12, 23-43

Sayeed, S., Li, J., and McClane, B.A., 2010. Characterization of virulence plasmid diversity among Clostridium perfringens type B isolates, Infection and Immunity, 78, 495-504

Selzer, J. et al., 1996. Clostridium novyi $\alpha$-toxin-catalyzed incorporation of GlcNAc into Rho subfamily proteins, Journal of Biological Chemistry, 271, 25173-25177

Seyed Sayyah, P., Golestani Eimani, B., and Pilehchian Langroudi, R., 2018. Cloning of Clostridium perfringens Iota toxin gene in Escherichia coli, Archives of Razi Institute, 73, 107-111

Shepard, L.A. et al., 2000. The mechanism of pore assembly for a cholesterol-dependent cytolysin: formation of a large prepore complex precedes the insertion of the transmembrane $\beta$-hairpins, Biochemistry, 39, 10284-10293

Shimizu, T. et al., 2002. Complete genome sequence of Clostridium perfringens, an anaerobic flesh-eater, Proceedings of the National Academy of Sciences, 99, 996-1001

Skarin, H., and Segerman, B., 2014. Plasmidome interchange between Clostridium botulinum, Clostridium novyi and Clostridium haemolyticum converts strains of independent lineages into distinctly different pathogens, PloS One, 9
Songer, J.G., 1996. Clostridial enteric diseases of domestic animals, Clinical Microbiology Reviews, 9, 216

Sori, H. et al., 2018. Evaluation of safety and immunogenicity of combined blackleg and hemorrhagic septicemia vaccine, African Journal of Microbiology Research, 12, 141-146

Springer, S., and Selbitz, H.-J., 1999. The control of necrotic enteritis in sucking piglets by means of a Clostridium perfringens toxoid vaccine, FEMS Immunology \& Medical Microbiology, 24, 333-336

Stevens, D.L., Aldape, M.J., and Bryant, A.E., 2012. Life-threatening clostridial infections, Anaerobe, 18, 254-259

Taherian Fard, A. et al., 2010. Cloning and expression of C-terminal of Clostridium perfringens type A enterotoxin and its biological activity, African Journal of Microbiology Research, 4, 1469-1474

Takehara, M. et al., 2017. Cellular entry of Clostridium perfringens iotatoxin and Clostridium botulinum $\mathrm{C} 2$ toxin, Toxins, 9, 247

Terpe, K., 2006. Overview of bacterial expression systems for heterologous protein production: from molecular and biochemical fundamentals to commercial systems. Applied Microbiology and Biotechnology, 72(2), 211-22

Thachil, A.J. et al., 2013. Vaccination of turkeys with Clostridium septicum bacterin-toxoid: evaluation of protection against clostridial dermatitis, Avian Diseases, 57, 214-219

Tweten, R.K., 1988. Nucleotide sequence of the gene for perfringolysin $\mathrm{O}$ (theta-toxin) from Clostridium perfringens: significant homology with the genes for streptolysin $\mathrm{O}$ and pneumolysin, Infection and Immunity, 56, 3235-3240

Tytell, A.A., and Logan, M.A., 1947. Immunization of humans and animals with gas gangrene toxoids, Journal of Immunology (Baltimore, Md.: 1950), 55, 233-244

Uzal, F. et al., 2010. Toxins involved in mammalian veterinary diseases, Open Toxinology Journal, 2, 24-42

Uzal, F.A. et al., 2014. Towards an understanding of the role of Clostridium perfringens toxins in human and animal disease, Future Microbiology, 9, 361-377

Verherstraeten, S. et al., 2013. The synergistic necrohemorrhagic action of Clostridium perfringens perfringolysin and alpha toxin in the bovine intestine and against bovine endothelial cells, Veterinary Research, 44, 45

Vilei, E.M. et al., 2011. Genetic and functional characterization of the NanA sialidase from Clostridium chauvoei, Veterinary Research, 42,2

Yan, X.-X. et al., 2013. Structural and functional analysis of the poreforming toxin NetB from Clostridium perfringens, MBio, 4, e00019-00013

Zaragoza, N.E. et al., 2019. Vaccine Production to Protect Animals Against Pathogenic Clostridia, Toxins, 11, 525

Zeng, J. et al., 2011. Potential protective immunogenicity of recombinant Clostridium perfringens $\alpha-\beta 2-\beta 1$ fusion toxin in mice, sows and cows, Vaccine, 29, 5459-5466

Publisher's note Springer Nature remains neutral with regard to jurisdictional claims in published maps and institutional affiliations. 